\title{
Symbolism and the Adoption of Fuel-Cell Vehicles
}

\author{
Reid R. Heffner*, Kenneth S. Kurani*, Thomas S.Turrentine*
}

\begin{abstract}
Since car buyers have limited practical experience with FCVs, direct study of FCV adoption is not feasible. However, consumer behavior toward other types of advanced-technology vehicles may offer clues about how the market for FCVs will develop. Research of hybrid-electric vehicles (HEVs) indicates that consumers adopt these vehicles partly because of the vehicles' symbolism. Any vehicle can serve as a symbol; it can represent larger ideas, meanings that frequently relate to the identity of the vehicle's owner. This qualitative research study examines early buyers of HEVs to understand the symbolic meanings they perceived in their vehicles and the role symbolism played in their vehicle purchases. Findings from these buyers are then prospectively applied to the future market for FCVs. The study includes four specific recommendations to increase the possibility that FCV buyers can access and communicate relevant symbolic meanings with their vehicles.
\end{abstract}

\section{Keywords: Marketing, Market Analysis, Fuel Cell Vehicles, Hybrid Electric Vehicles}

\section{INTRODUCTION}

Why will consumers buy fuel cell vehicles (FCVs)? Studies of American car-buyers suggest there is strong potential demand for FCVs; in a recent Harris Interactive poll [1], 52\% of participants stated that they were likely to purchase an FCV as their next vehicle. However, it is unclear whether results like these are meaningful since there are no FCVs available in the marketplace, and critical questions about the cost, durability, performance, and refueling infrastructure of these vehicles remain unanswered. Until consumers have direct experience with FCVs, they are probably unable to accurately tell researchers whether they will buy an FCV.

Since it is difficult to assess the FCV market before FCVs are available to consumers, this study adopts a different approach. It looks for potential insights about consumers and FCVs from the market development of another advanced-technology vehicle, the hybrid-electric vehicle (HEV). Since HEVs were introduced in the U.S. market in 1999, HEV market share has grown steadily to almost $2 \%$ of all light-duty vehicle sales [2], a figure that analysts estimate will grow to $3-6 \%$ by the end of the decade [3]. While overall HEV sales remain small relative to the total U.S. light-duty vehicle market, sales of individual HEV models are reaching mainstream volumes. For example, sales of the most popular HEV, the Toyota Prius, now exceed 100,000 units per year, placing the Prius in the top $20 \%$ of U.S. nameplates by sales volume [4].

In this study, we conducted a thorough assessment of

* University of California, Davis - Institute of Transportation Studies, One Shields Avenue, Davis, California 95616 USA. e-mail: rrheffner@ucdavis.edu; knkurani@ucdavis.edu; tturrentine@ucdavis.edu the automobile purchases made by 25 early HEV buyers - that is, people who bought a Honda Insight, Honda Civic Hybrid, or Toyota Prius. In discussion with these households, it became clear that HEVs provided their owners with more than transportation. HEVs served as powerful symbols of owners' values and viewpoints, and thus HEVs made a strong statement about the people who owned them. Such symbolism was an important purchase driver for these HEV buyers.

This study focuses on the symbolism of HEVs and speculates on the role symbolism may play in future markets for FCVs. From our analysis of early HEV buyers, we derived key findings about vehicle symbolism and developed four recommendations to enhance the marketability of FCVs in the future.

\subsection{Vehicles as Symbols}

Any automobile may be a symbol: one look at automotive advertising tells us that manufacturers are selling more than horsepower and headroom. While automobiles provide transportation, they also can represent ideas like freedom, affluence, youth, or risk-taking. When automobiles symbolize meanings like these, they make a statement about the vehicle owner, identifying him as a certain type of person. Making judgments about someone based on a product they use (in this case, a car) is known as consumption stereotyping, and studies show it is prevalent with regard to automobiles. People evaluate themselves and others based on the vehicles they own [5]. In one study of consumption stereotyping, respondents used automobiles to predict owners' intelligence, life satisfaction, and behavior toward others [6].

Heffner, et. al. [7] note that individuals use the symbolic meanings in automobiles to develop and maintain their self-identities. By selecting a particular vehicle, car buyers can define and communicate who 
they are, expressing real or desired interests, beliefs, values, and social status. Self-expression may seem trivial when compared to practical considerations such as whether the car fits the buyer's budget or offers enough room for passengers. However, Giddens [8] notes that self-identity is often paramount in people's choices, outweighing utilitarian or economic considerations. This is because, as Giddens explains, active self-definition has become an essential task in the life of the modern individual. Each person must constantly be developing a self-narrative: a "story" that tells himself and others who he is. Symbolic objects like automobiles are essential tools in this process of self-definition.

\subsection{Symbolism and Advanced-Technology Vehicles}

Not surprisingly, the meanings consumers associate with particular automobiles have been shown to affect purchase intentions [9] as well as actual purchases [10] of those vehicles. Past research also suggests that symbolic meanings are important to early buyers of advanced-technology vehicles. In their examination of battery-electric vehicles (BEVs), Gjøen and Hård [11] conclude that the symbolic meanings of BEVs had a significant influence on the adoption decisions of initial owners. Early HEV buyers in the United States also emphasized symbolic meanings in their vehicles, describing HEVs as important symbols of concepts such as social responsibility and environmental stewardship $[12,13]$. Many HEV owners willingly acknowledge the role of their vehicles in the expression of self-identity. In one survey, 31 percent of U.S. HEV buyers said they purchased an HEV because it "makes a statement about me" [14].

\section{METHODS}

Data for this study were collected through qualitative interviews, a method that offers two main advantages. First, HEVs are new types of automobiles. For any new technology product, it is likely that consumers will develop their own perceptions of its significance and value. McCracken [15] notes that qualitative research methods excel in uncovering how individuals think about, use, and value new goods because such methods allow participants to discuss these goods using their own words and frameworks. Second, qualitative interview techniques overcome some of the challenges to examining symbolic meaning and its effect on behavior. Zaltman and Coulter [16] warn that consumers can have difficulty interpreting and explaining the symbolic meanings attached to a product. Individuals may also deliberately conceal symbolic meanings or downplay their importance $[17,18]$.

This study examined 25 households that owned HEVs and resided in northern California. Interviews were conducted in participants' homes using a semi-structured protocol. Participating households were interviewed between November 2004 and March 2005. The typical interview lasted two hours; it involved two researchers and all members of the household who were involved in the vehicle purchase. The interview protocol included the following phases:

1. Household Vehicle History: A general review of household members, vehicles they currently own, vehicles owned during the past decade, and current vehicle use patterns.

2. Purchase Narrative: A narrative [19] of the hybrid purchase told by the households with limited prompting by researchers. The narrative gives participants the opportunity to tell the story of their HEV purchase in their own words and with a focus on aspects that they deem significant and "communicable."

3. Symbolic Meaning Analysis: A series of questions and exercises designed to assist participants to think about and verbalize the symbolic meanings of their HEV and other vehicles. Visual techniques [16] were used to complement verbal descriptions of meanings.

4. HEV Benefits and Disbenefits Analysis: Discussion in which participants identify the perceived advantages and disadvantages to buying an HEV, and explain the importance of these advantages and disadvantages in their own HEV purchase. Researchers prompt discussion and apply laddering techniques [20], a method used to connect product attributes to underlying consumer values.

5. Vehicle Preference Exercise: A stated adaptation exercise in which researchers propose replacing the household's HEV with another vehicle. Replacement vehicles are often hypothetical options, and are customized for each household based on prior phases of the interview.

\section{FINDINGS AND RECOMMENDATIONS}

The following section presents four recommendations for manufacturers and policymakers who aim to promote FCVs in the future. Each recommendation is rooted in findings from our research of HEV owners. The findings are discussed first, then each recommendation is explained and specific examples are included to highlight how the recommendation can be implemented.

\subsection{FCVs Must Provide Symbolic Meanings}

When asked why they purchased their HEVs, households in this study cited one or more symbolic meanings as important in their purchase. They saw the $\mathrm{HEV}$ as a symbol of preserving the environment, saving money, gaining independence from oil producers, and adopting new technology. (The symbolic meanings of HEVs are summarized in Figure 1). The association of these meanings with HEVs should come as no surprise: the same meanings have been publicly discussed (and debated) in the American popular press and by government regulators, interest groups, civic leaders, and celebrities.

For the majority of the households in this study, the HEV represented the right thing to do for the ecosystem. It identified its owner as someone who was aware of the 
significant environmental issues facing the planet and the human race, and as a person who was willing to do his/her part to conserve precious natural resources. Almost half of households interviewed also connected their HEVs with the idea of saving money. For these participants, the HEV represented an intelligent purchase that would allow its owner to spend less money on gasoline over time. A handful of households also associated HEVs with independence from oil companies and oil-producing states. Many of these owners accused multinational energy providers and Middle Eastern oil producers of exploiting the consumer, damaging the national economy, fouling the environment, and resorting to violence and coercion to keep petroleum supplies flowing. For these HEV owners, the HEV represented an important step away from petroleum and a disassociation with those who produced it. Finally, some participants stressed the technological meaning of their HEVs. To them, the HEV represented the most advanced automotive technology available, and signaled a dramatic advance over the conventional internal-combustion engine.

Few households conducted a thorough analysis of the HEV's environmental benefits, lifecycle cost savings, impact on oil producers, or technological credentials. Many buyers did research their vehicles and, to the best of their ability, confirmed that the vehicles delivered the desired functionality. Indeed, some households looked to publications like Consumer Reports for confirmation of HEVs' money-saving potential, to magazines like Popular Mechanics for an assessment of the new technology, and to nonprofit groups such as the Sierra Club for verification of HEVs' ecological credentials. But not a single household calculated how much their HEV reduced carbon dioxide emissions or how much money their HEV saved them in fuel each year. More strikingly, many households avoided behaviors that would have brought them closer to their purported goals. Among owners that associated their HEVs with saving money, only one seriously considered purchasing an inexpensive, fuel-efficient economy car that many analysts suggest is a more financially-sensible choice. Among households interested in preserving the environment, few considered reducing vehicle use and increasing their use of more environmentally-friendly transportation alternatives, including bicycling and public transit.

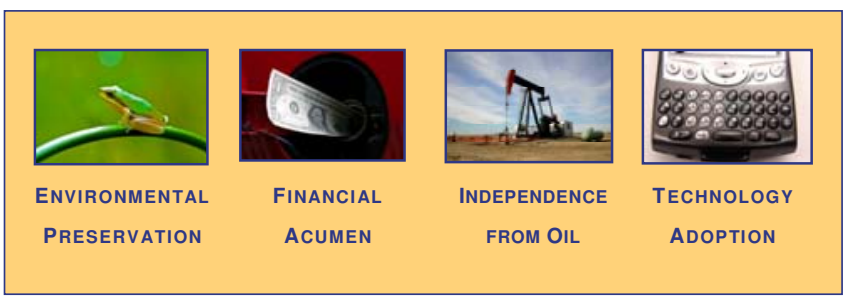

Fig. 1 Symbolic Meanings of HEVs

It is easy to label the behavior of these early HEV buyers as unreasonable, unless we consider the importance of symbolism in their purchases. While some households researched various environmental, financial, energy, and technological aspects of their HEVs, most relied more on what the HEV symbolized in these areas. Symbolic meaning explains why alternatives to the HEV were not considered. Bicycling or riding public transport may benefit the environment, but using these forms of transportation does not announce to others that one is concerned about the ecosystem. HEVs do make that statement, and for many early HEV buyers, communicating the idea of preserving the environment was as important as actually doing something to help the planet.

Sending the right message was also important to households who saw their HEVs as symbols of saving money. When making their vehicle purchases, these households ignored economy cars that provided relatively high mileage at much lower purchase prices than hybrid models. Participants, some of whom had owned economy cars in the past, explained that the message sent by these vehicles was different from HEVs. An HEV told the world that its owner was someone who had chosen to save money. In contrast, an economy car communicated that its owner had no choice: his/her budget was so constrained that an economy car was the only realistic option. Thus, vehicles such as the Honda Civic and Honda Civic Hybrid that looked almost identical and often were displayed on the same dealer lot were perceived by HEV buyers as very distinct vehicles. The difference had less to do with fuel economy ratings or purchase prices, and more to do with the desired symbolic meanings that were available only in the hybrid version.

There is an important lesson here in how consumers relate to new technologies. Too often analysts assume that it is the functional or economic benefits of a technological innovation that attract early buyers. Yet our households conducted little analysis of these types of benefits. Certainly part of the reason for this omission is that such analysis can be complicated, particularly for individuals who are not environmental experts, financial analysts, energy-industry professionals, or technologists. But another part of the explanation is that these households were not buying HEVs solely for their functional or economic benefits. For them, the real innovation was the new meanings the HEV provided. What households really bought were the ideas of themselves as people who cared about the environment, who made smart purchases, who could declare independence from oil, and who were on the cutting edge of technology.

The lesson for FCV proponents is that FCVs must offer clear symbolic meanings to differentiate them from other types of vehicles. Just as early buyers of HEVs sought meanings that were unavailable in other types of vehicles, early buyers of FCVs will also be looking for symbolism in their vehicles. It is possible that FCVs will offer some (or all) of the same meanings that are associated with HEVs. Environmental preservation, for example, is a likely meaning to 
associate with a highly-efficient FCV that generates no tailpipe emissions. Advanced technology is also a suitable meaning, since the fuel-cell represents a radically improved power source compared to the internal combustion engine. Yet we cannot assume that consumers will automatically perceive FCVs as environmental or advanced-technology vehicles. Consumer perception of FCVs' meaning will depend on what competing alternatives enter the market before FCVs, and how FCVs are seen relative to these alternatives.

To compete with HEVs and other vehicles, FCVs might improve upon existing meanings, offering buyers stronger, more authentic access to the ideas of environmental preservation, financial acumen, independence from oil, and technology awareness. For example, HEVs symbolize environmental preservation because they use less gasoline and generate fewer harmful emissions. FCVs may offer a stronger association with environmental preservation since the vehicles themselves have zero emissions and use fuel more efficiently that HEVs. However, questions remain about the well-to-wheel emissions of hydrogen-powered FCVs, particularly if the hydrogen is derived from fossil sources such as coal. Through the popular press and other sources, these issues already are making their way into the minds of consumers, leading them to question the symbolic connection between FCVs and the environment. Is hydrogen really cleaner? Are FCVs really more efficient if it takes large quantities of energy to produce the hydrogen fuel? Consumers' confusion about topics like these may prevent the association of FCVs with environmental preservation, and thus strip the FCV of a potentially important symbolic meaning. These questions are not merely hypothetical-already in these interviews we have heard both hope and uncertainty regarding hydrogen and FCVs.

One way to overcome this challenge is to focus on the symbolic meanings that resonate with consumers, and develop a vehicle (as well as fuel and fueling infrastructure) that is compatible with these meanings. For example, renewable hydrogen has the potential to strongly associate FCVs with the symbolic meaning of environmental preservation. If FCVs were powered only by hydrogen from renewable sources, the vehicles would have an undisputed claim as the cleanest, most sustainable form of motorized transport. In the mind of the consumer, an FCV that used completely renewable fuel would likely represent a significantly more environmentally-friendly option than other vehicles, including HEVs.

Of course, powering FCVs only with renewable hydrogen has significant repercussions for the design of the hydrogen generation infrastructure and the cost of hydrogen fuel. The more commonly-proposed approach is to generate hydrogen from numerous sources, including non-renewables such as natural gas and coal. Using fossil feedstocks may result in larger quantities of more affordable hydrogen fuel, but it ignores the symbolic meaning of the fuel and the FCV that uses it. As they did with HEVs, early buyers are likely to purchase FCVs because of the environmental symbolism they perceive in these vehicles. If the FCV's hydrogen fuel is seen as dirty - or at least no cleaner than gasoline - then the FCV's symbolic association with the environment may be severed and a significant source of the vehicle's value lost.

In addition to improving upon existing meanings, FCVs may also offer entirely new symbolic meanings that are not offered by HEVs or any other type of vehicle. While it is difficult to envision what these meanings may be, one possibility could be the idea of extended personal territory. Marsh and Collett [21] note that one appealing aspect of the automobile is that it provides the driver with a zone of safe, personal space similar to the home. Unlike a house, however, a vehicle is mobile - a "home on wheels" [21] - and thus allows the owner to transport part of his/her personal territory wherever he/she goes. Transporting personal territory may seem like a strange concept, but it is one of the reasons people are so comfortable traveling to new places in their automobiles. If the new destinations prove less welcoming than planned, drivers always are free to retreat to the portable personal territory they brought with them. Marsh and Collett also suggest that much of drivers' aggressive behavior toward others stems from this idea of personal territory. Drivers feel they must protect their "home on wheels" when it is threatened, and also feel safe enough within this territory to behave boldly (even aggressively) toward others.

FCVs may be uniquely suited to symbolize the idea of extended personal territory. Kurani, et. al. [22] observe that the FCV offers a unique feature that conventional vehicles and HEVs do not: the ability to cleanly, silently provide electricity, even when the vehicle is not in motion. Since "mobile electricity" [22] can be used to power a variety of devices as well as maintain the interior climate of the vehicle, the FCV truly is a small home on wheels or, as Kurani, et. al. call it, a "mobile activity locale" [22]. The mobile activity locale represents an extension of personal territory since it increases the number of activities an FCV owner can conduct in his vehicle. For example, with the proper equipment, the FCV can serve as an office or a kitchen, and others can join the owner at this "destination" to conduct business or enjoy a meal. The FCV owner not only has a mobile personal territory: he has a territory that can sustain a wider variety of activities, including more types of social interaction with other people. Today's consumers may have trouble envisioning exactly how they would use a mobile activity locale, but the symbolic meaning of extended personal territory may turn out to be an important selling point for early buyers of the FCV.

\subsection{FCVs' Symbolic Meanings Must Have Personal Significance for Buyers}

As households discussed the ideas of environmental 
preservation, financial acumen, independence from oil, and technology adoption, it became clear that each of these ideas was linked to another set of meanings related to the identity of the owner. For example, early buyers of HEVs were not just telling the world that they were people who cared about the environment; they were also signaling that they were ethical individuals who cared about the welfare of others, including future generations. For these buyers, the HEV symbolized an individual contribution to the common good, and the idea that people could work together to overcome the problems that faced them, even if the problems were on a global scale. Many households who purchased their HEVs because of the vehicles' environmental symbolism readily acknowledged that their vehicle alone made little difference in reducing global warming or clearing urban smog. But whether their actions were effective wasn't as important as their belief that their actions were right. Through their purchase of an HEV, these owners were demonstrating that they were people who acted on their ethical beliefs, and that they were participating in a broader collective solution to a severe societal problem.

The other symbolic meanings of the HEV had personal significance to owners as well. HEVs did not just symbolize the idea of saving money: they depicted their owners as intelligent, sensible people who made smart choices in all areas of their lives. Particularly for younger HEV owners, the HEV also signaled that they possessed a level of maturity that was absent in many of their peers. HEVs symbolized independence from oil companies, but they also signaled an owner who stood up for himself and was willing to combat those who wronged him/her. HEVs symbolized new technology, but were more than just another gadget. HEVs identified their owners as people who were unique individuals "ahead of the crowd" as one participant explained. HEVs showed that their owners were leaders, visionaries who recognized the potential of new developments before others did.

The HEV buyers in this study purchased access to symbolic meanings and the ideas of themselves as certain types of people. We suggest that FCVs must also provide this combination of symbolic meanings that have deep personal significance for buyers. This means that the vehicles, fueling infrastructure, and other aspects of the ownership experience must deliver symbolism on two levels. As discussed earlier, FCVs may be associated with environmental preservation by fueling them with renewable hydrogen. But in addition, FCVs should also have authentic links to the underlying ideas associated with environmental preservation: ethics, concern for others, and community-orientation.

How can an automobile symbolize an idea like concern for others? One example is by offering safety beyond mandated levels. Safety systems such as air bags and anti-rollover systems have practical value, of course: they prevent drivers and occupants from being injured in a crash. But safety systems, particularly when purchased by parents, also can symbolize concern for others, especially concern for their own children. Buying the latest safety devices on a new vehicle can symbolize that a parent cares about preventing harm to his/her offspring. This is precisely the message that many HEV owners talk about sending with their HEVs. Because HEVs are kinder to the natural environment, owners explain that HEVs contribute to a cleaner, more prosperous world for their children and grandchildren. Thus, two seemingly unrelated features - a hybrid powertrain and safety systems - contribute to the same underlying symbolic meaning.

If FCVs, therefore, were to provide the most advanced occupant protection systems available, this could ensure a credible symbolic linkage to the idea of concern for others. FCVs also could go one step further and offer advanced pedestrian safety systems. For many HEV owners, concern for others extends beyond their own families and into the general public. An FCV equipped with an advanced pedestrian safety system signals an owner who is thinking not just of himself, but also of others on the road, including the most vulnerable road users - pedestrians.

Home refueling may also offer symbolic meanings with personal significance to FCV buyers. Unlike gasoline-powered HEVs and conventional vehicles, FCVs might be fueled at the driver's home using hydrogen derived from either reformation or electrolysis. One important aspect of home refueling is its symbolism of independence and its definition of the user as an autonomous individual. FCV owners who refuel at home make a complete break with the petroleum infrastructure. Whether or not home refueling is cheaper or more convenient, the symbolic meanings of independence and individual autonomy may be home refueling's chief advantages. The symbolism of home refueling could be enhanced further if it used solar electricity collected from the FCV owner's own roof. Using solar electricity for distributed electrolysis is hardly the most efficient or economical way to generate hydrogen fuel, but it is probably the most meaningful to some consumers. Even if only a portion of the electricity used is from their solar panels, FCV owners with this type of home refueling can tell a powerful story about both environmental concern and personal independence. Ultimately, it is these types of symbolic meanings (rather than financial calculations or technical schematics) that they will share when telling others about FCVs.

\subsection{FCVs Should Enable Communication}

Symbolism is about communication: we use symbols to express ideas to ourselves and to other people. With HEVs, communication occurs in two ways. The first is that the vehicles "speak" for themselves, broadcasting their symbolic meanings to those who see the vehicles. The majority of households in this study recognized the HEV's potential to "send a message" or "make a statement" and embraced this aspect of their vehicles. In fact, the communicative ability of HEVs is an important reason for purchase for roughly a third of $\mathrm{HEV}$ buyers 
[14]. One example is a participant in this study who likened his HEV to a billboard that displayed symbolic meanings to everyone on the road: "every time you are on the freeway" he explained, "you are advertising."

The other form of communication that occurs with HEVs is the conversations HEV owners have with others. All of the households in this study had talked to others people about their HEV, and many actively sought out these discussions. During the time of this study, HEVs were still a relatively new phenomenon, and many owners were regularly approached by curious strangers in parking lots and gas stations. In particular, owners who perceived environmental symbolism in their HEVs were eager to engage others and educate them about HEVs. In some cases, households' communication efforts bordered on the extreme: some handed out sales literature, provided test drives to complete strangers, and offered lengthy testimonials to potential buyers. Much of this advocacy was rooted in the desire to see HEVs become more widely accepted. For environmentally minded owners, each new HEV on the road represented less pollution and resource use. Many described their vision of a world where everyone drove hybrids: a place where people respected the environment and understood how to care for it. Since a single vehicle could have little tangible impact on environmental issues, involving others was a necessary step in order to bring about real ecological improvement. Communication, particularly with the non-owners who were unaware of hybrid technology, was the first step toward securing their involvement.

Yet there was another reason for HEV owners' communication with others. In talking about their HEVs, owners also were able to talk about themselves - to communicate who they were. Sharing personal identity was perhaps most obvious in those owners who were less concerned about the environment but nonetheless actively communicated with others about their vehicles. Talking with others about HEVs didn't save them more money or make the technology in their vehicles more advanced, but it did underscore the personally significant meanings associated with these ideas. Owners who felt their HEVs symbolized financial acumen told others about their high gas mileage and described how little money they were spending on fuel. In the process, they reinforced the idea of themselves as smart consumers. The same can be said for owners who perceived the meaning of technology adoption in their HEVs. By telling others about the HEV's advanced features (such as all-electric drive or wireless networking capabilities) these owners were confirming the image of themselves as people who understood new technology, and as unique leaders who could see the future long before the mainstream.

FCVs (as well as their refueling infrastructure and other aspects of the ownership experience) must enable communication about the vehicles. The goal is to engage FCV owners in making non-owners aware of FCVs. This can occur in two ways: either by making FCVs obvious so that they can "speak" for themselves, or by creating situations in which owners and non-owners can interact and discuss FCVs. The information that is exchanged in either form of communication is not just technical data on fuel cells or hydrogen fuel, it is also information about what the vehicles symbolize. Many car buyers will never take the time to fully understand the inner workings of a fuel-cell powerplant, just as many HEV owners in this study did not understand the technical details of their car's hybrid drivetrain. What individuals do understand is what HEVs symbolize: ideas like environmental preservation, saving money, gaining independence from oil, and embracing new technology. As innovations like HEVs and FCVs diffuse through a population, it is symbolic meanings (as well as technical information) that earlier adopters share with others. For FCVs to be successful, non-owners must learn what the new vehicles mean, and their understanding of the vehicles' symbolic meaning may then lead to purchase.

One way to allow FCVs to communicate effectively is to make the exterior of FCVs easily distinguishable from other vehicles. This does not necessarily mean that manufacturers must develop unique platforms for FCVs, nor does it mean that all FCVs must employ radically new designs. However, both of these measures may be helpful to ensure that the exterior styling of FCVs is distinctive enough so that the vehicles are easily identified. Exactly how different exterior styling should be is likely to be a matter of personal taste for early buyers. Among this study's HEV owners, some were attracted to the Toyota Prius because of its unique styling, while others preferred the Honda Civic Hybrid because it closely resembled a conventional vehicle. However, nearly all of these owners felt that their vehicles were easily distinguished from conventional offerings, and this is what is important. Ultimately, automakers may have the most success by using the strategy Toyota has applied to its HEV models - by offering a variety of FCVs, some of which incorporate radically new styling and others that rely on more traditional designs (coupled with prominent exterior badging). In all cases, however, FCVs should be easily identified as FCVs.

Several factors can increase communication between owners and non-owners. Parking and refueling infrastructure, if designed properly, can place FCVs and their owners prominently in front of non-owners and create the conditions for interaction. Providing hydrogen refueling at existing gasoline stations, for example, would create a situation in which non-owners would observe an FCV and could briefly talk with its owner. In fact, gas stations were a common venue for non-owners to approach early HEV buyers to ask about their vehicles. Parking lots are another location where early HEV buyers report communicating with others about their vehicles. Designated parking for FCVs, particularly if it were prominently located close to pedestrian traffic around a store or mall, would make FCVs visible to non-owners and provide brief opportunities for interaction when owners entered or 
exited their vehicles. Of course, it cannot be assumed that every early FCV buyer will be a willing advocate for the technology. However, those who wish to have less interaction with non-owners can opt to fuel at home or can avoid designated FCV parking areas. Owners who are eager to educate others - as many of early HEV buyers were - can leverage parking and refueling infrastructure to facilitate this interaction.

\subsection{FCV Proponents Should Monitor and Participate in the Discourse on FCVs}

Automotive manufacturers typically use advertisements to associate symbolic meanings with their vehicles. Until recently, advertisements for HEVs were rare in the United States, yet HEVs still managed to acquire and display symbolic meanings. This occurred because advertisers are not the only actors who associate meanings with automobiles. Meanings are developed through discourse, essentially an ongoing "discussion" that occurs in society. Advertisements are part of the discourse, as are messages from sources such as scientists, journalists, political leaders, celebrities, and HEV owners. HEVs came to be linked with environmental preservation not because automakers spent millions of dollars in advertisements, but because reporters, academic researchers, leaders of environmental groups, and HEV owners decided these vehicles were good for the environment and shared their views with others. As more voices confirmed the connection between HEVs and the environment, the linkage grew stronger, and the HEV became a symbol for environmental preservation. A multitude of voices within the discourse, rather than any one specific actor, assigned symbolic meaning to the HEV.

As McCracken [15] notes, individuals ultimately decide for themselves what an innovation like the HEV means, and they may not always accept the symbolic meanings that advertisers or anyone else assign to a product. In addition, the symbolic meanings discussed in the discourse can be diverse, so individuals must select the meanings they feel are appropriate. For example, several HEV owners in this study were attracted to the fact that their HEVs symbolized environmental preservation, but they were concerned that this meaning could be interpreted negatively. While some HEV owners wanted to be seen as ethical people who cared about others, they recognized that they might be perceived as extremists who favored environmental preservation above all else, or as wimpy, wishful idealists who were out of touch with the real world. (Figure 3 presents a list of the major positive and negative symbolic meanings of the HEV that were perceived by participants in this study.)

Positive: ETHICAL, SMART, INDEependent, Unique, INNOVATIVE Negative: Radical, IRRATIONAL, FOOLhaRdy, HaRmful

Fig. 3 Positive and Negative Meanings of HEVs
Other negative meanings that participants discussed included the idea of HEVs as a foolish purchase. Numerous articles in the popular press have examined whether buying an HEV is a sound financial decision, and many authors have concluded that buyers are ignoring economics in order to make a social statement (for example, see [23]). The idea of an $\mathrm{HEV}$ as foolhardy, of course, stands in direct opposition to the perception of many HEV owners that their HEV identifies them as a smart consumer. Other press articles also have portrayed HEVs as potentially harmful, claiming emergency personnel responding to an accident involving an HEV could be injured by the high voltage wires inside the HEV (for example, see [24]). This characterization of the HEV as a threat to well-intentioned rescuers directly opposes the meaning many HEV owners see in their vehicles: HEVs as symbols of caring about other people.

Among this study's HEV owners, individuals coped with contrasting symbolic meanings in various ways. One technique was to seek a balance of meanings. While some owners unashamedly bought their HEVs to make an environmental statement, others liked the fact that the HEV expressed both an idealistic concern for the ecosystem as well as a practical statement about saving money. As one participant explained, he and his wife saw their HEV as a symbol of altruism, as the "right thing to do" for the world they lived in. But they were also smart, sensible people, and they wouldn't buy a car simply to show concern for the environment. They were pleased that their HEV sent a message about saving money as well: it showed that while they cared about doing the right thing, they also were reasonable people who made sound financial choices. For other households, obtaining a balance of meanings involved changing their behavior. One owner, who traded in his BMW for a Toyota Prius, struggled with the idea that other drivers might identify him not as an enlightened conservationist, but as an annoying weakling struggling along the highway in an underpowered econobox. To prevent misinterpretation of his HEV's meaning, he added performance tires to his Prius and drove it fast - faster even than he used to drive his BMW - during his first few months of ownership. While he suffered a fuel economy penalty, fast driving balanced the symbolic meanings of his vehicle. The HEV told others that he cared about the environment; speeding by them showed that he still enjoyed the thrill and risk of performance.

Another technique HEV owners used to manage the diverse meanings of their vehicles was to participate directly in the discourse. Communicating with non-owners was one way to share their ideas about HEVs; another was to interact with other HEV owners in person or online. Several owners also felt that their HEV purchases had opened a dialogue with automakers. In buying an $\mathrm{HEV}$, these owners saw themselves sending a message of encouragement to companies that were producing the vehicles, and an issuing an 
admonishment to those who were not. As noted earlier, HEV owners' communication was a way to bring others into the HEV fold as well as a technique for individual self-expression. But it was also a way for owners to maintain control of what HEVs meant: to ensure that their voices were heard in the noisy public discourse that surrounded a new type of vehicle.

Those who want to encourage adoption of FCVs must monitor and participate in the societal discourse about these vehicles. FCV proponents must realize that the discourse involves many voices. This is because modern information technology allows anyone with an Internet connection to easily participate in the public discussion about what products like the FCV mean. In the case of HEVs, websites and discussion groups that focused on these vehicles developed quickly, and most were independent from major media outlets. Increasingly, consumers look to blogs and discussion groups as well as articles from traditional media sources to determine the meaning of a new innovation. The result is that a wide, diverse discussion occurs around new technologies like FCVs. FCV proponents cannot expect to attach important symbolic meanings to FCVs simply by advertising. They will also have to monitor other voices in the discourse, encouraging those with positive messages and countering those who attempt to attach negative meanings to FCVs. This is not a process that any manufacturer or policymaker can expect to control, but they can actively participate and encourage those who share their pro-FCV views.

\section{CONCLUSION}

Although FCV buyers may be attracted to new functionality such as electric drive or mobile electricity, they will also seek symbolic meaning in these vehicles. As demonstrated in the U.S. HEV market, some early buyers are willing to pay more and even wait weeks or months for delivery of their vehicles in order to acquire symbolic meanings. Most of the HEV buyers interviewed for the research discussed here also wished to communicate these meanings to others, either by displaying their vehicles or through discussions with other people. For this study's households, the HEV purchase proved to be more than the acquisition of a new automobile. Buying an HEV gave them access to a symbol of environmental preservation, financial acumen, independence from oil, and technology awareness. In addition, HEVs also offered underlying, personally-significant meanings, identifying their owners as people who were ethical and caring, intelligent and organized, autonomous and strong, and/or unique and visionary.

The future success of FCVs will depend on the symbolic meanings that are attached to these vehicles. These meanings are developed through a societal discourse that involves numerous actors. As the HEV market has shown, no single actor controls the discourse, and automakers' advertising is not always the most influential voice. Ultimately, the development of symbolic meanings, like the development of new technology, takes time. Consumers must not only learn how a new technology works, but they also must learn what the new technology means. As automakers evaluate the market potential of FCVs, they must understand that simply making a fuel-cell powered model available in the marketplace is not enough. It will take a commitment to the technology and a willingness to develop the right symbols for customers in order to advance the FCV market.

\section{REFERENCES}

[1] Harris Interactive. "The Harris Interactive AUTOTECHCAST Study Finds Strong U.S. Consumer Interest in Enhanced Fuel Economy and Safety Technologies." December 8, 2004.

[2] CNW Marketing Research, Inc. July 2006 vs July 2005 Sales by Model. August 2006

[3] Berman, Bradley. Growth in Hybrid Markets: Forecasts of Hybrid Sales. hybridcars.com. December 2005.

[4] Automotive News. U.S. light-vehicle sales by nameplate, Dec. \& YTD. January 9, 2006.

[5] Grubb, E. and Hupp, G. "Perception of Self, Generalized Stereotypes, and Brand Selection." Journal of Marketing Research. Volume 5. February 1968.

[6] Belk, R.; Bahn, K.; Mayer, R. "Developmental Recognition of Consumption Symbolism" Journal of Consumer Research. Vol. 9, Iss. 1. June 1982.

[7] Heffner, R.; Turrentine, T.; Kurani, K. A Primer on Automobile Semiotics. UCD-ITS-RR-06-01. January 2006

[8] Giddens, A. Modernity and Self-Identity. Stanford University Press: Stanford, CA. 1991.

[9] Ericksen, M. "Using Self-Congruity and Ideal Congruity to Predict Purchase Intention: A European Perspective." Journal of Euro - Marketing. Vol. 6, Iss. 1. 1996.

[10] Sirgy, M. J. "Using Self-Congruity and Ideal Congruity to Predict Purchase Motivation." Journal of Business Research. Vol. 13. 1985.

[11] Gjøen, H. and Hård, M. "Cultural Politics in Action: Developing User Scripts in Relation to the Electric Vehicle" Science, Technology, and Human Values. Vol. 27, No. 2. Spring 2002

[12] Oregon Environmental Council. Survey of Oregon Hybrid Gas-Electric Car Owners. July 2003

[13] Kurani, K. and Turrentine, T. Automobile Buyer Decisions about Fuel Economy and Fuel Efficiency. ITS-RR-04-31. September 2004

[14] CNW Marketing Research, Inc. Hybrid Motivators. March 2006

[15] McCracken, G. Culture and Consumption. Indiana University Press. 1988

[16] Zaltman, G. and Coulter, R. "Seeing the Voice of the Customer: Metaphor-Based Advertising Research." Journal of Advertising Research. July/August 1995.

[17] Steg, L.; Vlek, C.; Slotegraaf, G. "Instrumental-reasoned and Symbolic-affective Motives for Using a Motor Car" Transportation Research Part F. Volume 4. 2001.

[18] Aaker, D.; Kumar, V.; Day, G. Marketing Research. John Wiley and Sons: New York. 2004.

[19] Mishler, E. Research Interviewing. Harvard University Press: Cambridge, MA. 1986.

[20] Reynolds, T. and Gutman, J. "Laddering Theory, Method, Analysis, and Interpretation." Journal of Advertising Research. February/March 1988.

[21] Marsh, P. and Collett, P. Driving Passion. Jonathan Cape, London. 1986.

[22] Kurani, K.; Turrentine, T.; Heffner, R.; Congleton, C. "Prospecting the Future for Hydrogen Fuel Cell Vehicle Markets" in The Hydrogen Energy Transition. Canon, J. and Sperling, D., eds. Elsevier Press. 2003

[23] Valdes-Dapena, P. "Hybrids: Don't buy the hype" Money. September 26, 2005.

[24] Schneider, G. "New Auto Safety Features Pose Threat to Rescue Workers." Washington Post. November 25, 2003. 